\title{
Soft Computing approach to enhance the Performance of AODV (Ad-hoc On-Demand Distance Vector) Routing Protocol using Active Route TimeOut (ART) Parameter in MANETs
}

\author{
Bonu Satish Kumar ${ }^{1}$, Saritha Bisai ${ }^{2}$, Palo Sangeetha ${ }^{3}$,Sagiraju SrinadhRaju ${ }^{4}$, Bosubabu Sambana ${ }^{5}$, \\ TataRao Vana ${ }^{6}$, Krishnardula Pavankumar $^{7}$
}
${ }^{1}$ Associate Professor, Department of Computer Science and Engineering, Raghu Engineering College (A), Visakhapatnam, Andhra Pradesh, India
${ }^{2}$ Assistant Professor, Department of Computer Science and Engineering, Lendi Institute of Engineering and Technology (A), Vizianagaram, Andhra Pradesh, India
${ }^{3}$ Assistant Professor, Department of Computer Science and Engineering, Lendi Institute of Engineering and Technology (A), Vizianagaram, Andhra Pradesh, India
${ }^{4}$ Associate Professor \& HOD, Department of Computer Science and Engineering, Raghu EngineeringCollege (A), Visakhapatnam, Andhra Pradesh, India
${ }^{5}$ Assistant Professor, Department of Computer Science and Engineering, Raghu Engineering College (A), Visakhapatnam, Andhra Pradesh, India
${ }^{6}$ Assistant Professor, Department of Computer Science and Engineering, Raghu Engineering College (A), Visakhapatnam, Andhra Pradesh, India
${ }^{7}$ Associate Professor, Department of Computer Science and Engineering, Raghu Engineering College (A), Visakhapatnam, Andhra Pradesh, India

Article History: Received: 11 January 2021; Accepted: 27 February 2021; Published online: 5 April 2021

Abstract: While its advancement inside MANETs, the AODV routing protocol convention has been and stays a
powerful and gainful examination protocol, with association with its course Active Route Timeout (ART),
AODV utilizes a predictable worth that demonstrates the time and the course which may stay dynamic in the
directing table. A long period of the course might be chosen powerfully, dependably through the estimation, as
opposed to reliable worth. For this reason, a Fuzzy rationale framework is utilized to procure the versatile
qualities for ART dependent on the transmitter conditions and interceding hubs.As indicated by the pre-essentials
of the International Engineering Task Force (IETF), we shouldn't be taking stil qualities in the powerful atmosphere.
Subsequently, ART's tweaking of turncoat esteems is accomplished by applies fluffy principles on the info
factors hop-count, Sent Control Packet, and Nodes Number. AODV convention yield is assessed after the
utilization of Fuzzy based methodology. The proficiency of AODV and FBARTAODV Routing Protocols for
Mobile Ad Hoc Networks will be examined with results. In this paper we give outcome show so as to the
FBARTAODV perform enhanced compared to the in progress AODV. Keywords: AODV, ART, FBARTAODV, Routing protocols.

\section{Introduction}

Wireless Ad-hoc Networks, are network with no offices together with base platforms or passageways. A few steering conventions contain be planned towards allow the On-the-Fly formation of networks, and it is a gathering information of PCs that utilization a bunch of basic correspondence conventions interconnected carefully to share assets situated on or given by the network hubs [1].

Several computers are connected through cables in a wired network. Wireless networks are an evolution in the networking technology where the systems are not connected through cables [2]. The ever-growing wireless networking technology uses radio waves to communicate between the network nodes.

\section{Ad-hoc Networks:}

Ad-hoc networks are an additional boundary near the wireless networking communication, which doesn't depend on any switches for communication because of its dynamic system. All things considered, the communication is over and done with by sending the information between the hubs with the assistance of a directing channel with a routing algorithm.

The life span estimation of the route is perhaps the majority extensive boundary to plan of particularly an Adhoc routing protocol on demand, along with boundary determines the distance end to end of the routes /a functioning way inside the-route / a functioning way inside the routing table in support of successful broadcast of the packets, this is to guarantee that no endeavor is made by the directing table to decide another course or potentially erase an all-around dynamic/existing course inside its life expectancy despite the fact that a few routes are not working, too long life-time of the route will reason to end in refreshing the steering table [14]. 
This resolve exists influenced by significant routing delay and overhead control on or after endeavors near communicate through non-existent routes. Then again: the too short a life expectancy of the routes resolve prohibit those dynamic routing protocol from the routing table, and it determination make the steering convention run the disclosure interaction once more for those routes, bringing about a critical deferral in directing and overhead rush hour gridlock because of the new routes filter [3]. Basically, this implies that the protocol designer to plan actual their needs to thoroughly pick and choose the estimation of route duration to reflect the genuine accessibility of source to destination routes.

In this present research work, we analyses and examine structures based on input values to desired outcomes by the functionaries as "AODV" immediate routing protocol is laid out along with, the method is clarified in related work, alongside Simulation methods is accessible in outcomes, and discoveries are planned to execute simulation module by the real-time environment with valid and verifiable executable results.

\section{AODV}

The Ad-hoc On-Demand Distance Vector (AODV) routing protocol [13] was created for use in impromptu versatile organizations. It qualifies the clients for discovering and keeps up routes in the network in favor of new or different clients, at whatever point required. AODV was invented by E. Belding Royer, C. Perkins on July 2003 at Nokia research Center and UCB. In earlier 1997, permanent life-time route value is connected nodes [3], it's called Active Route Timeout (ART), and these indicate the point in time in which the pathway stays dynamic into the direction-finding access.

As a result of the intricacy of this constancy, not extremely many network developers attempts to utilize duration esteem for the flexible route. Progressed statistical tools are utilized to forecast the lifetime of the adaptable route, which is exceptionally mixed-up to understand [4]. These numerical models bring about nonlinearity, a few levels of core Mobility predictable error.

In this paper, adaptable assurance of the existence of the route is planned utilizing Fuzzy Logic, and these is considering suitable to the uncertainty connected through assessing node/hub mobility and mathematical model disadvantages. The portrayal of the part capacities (Fuzzy Sets) and rule-based to build up the new framework, call Fuzzy ART, be planned. This new strategy is evaluated with the AODV routing protocol convention, and accepted to be noticed in favor of extra direction-finding conventions of Ad-hoc Networks as well [5].

\section{Related work}

a) Fuzzy Logic

Fuzzy Logic Toolbox offer MATLAB functionalities, applications, along with a Simulink structure on behalf of the investigation, plan, as well as Simulation of Fuzzy Logic-based frameworks, and we need existing software simulations works and guide to you during the executable planned procedures of Fuzzy inferencing frameworks.

To robust a few system of information yield on input-output, we be able to bring together a Fuzzy methods. In this framework, we know how to utilize an adaptive approach like Adaptive Neuro-Fuzzy Inference Systems (ANFIS) to simplify this technique, which is available in Fuzzy Logic Toolbox Software [6]

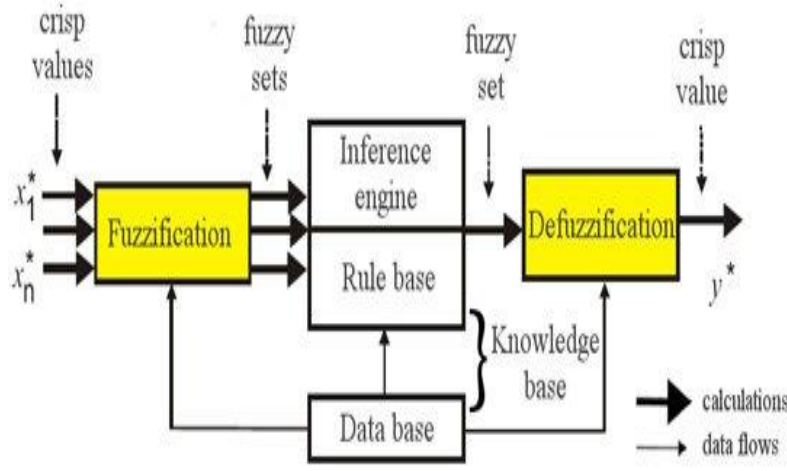

\section{b) FBARTAODV}

This strategy "Fuzzy Based Active Route Timeout AODV (FBARTAODV)" is built up next to it's huge quantity of Fuzzy rationale rules and conduct of participation capacities. This model registers dynamic course breaks related to the organization size of upto 50 hubs or nodes [14], along with language factors related to the 
info variable 'Hop-Count' are Low (L), Medium (M), and High $(\mathrm{H})$. The etymological variable related to the info variable the 'SentCntrlPkt' is Low (L), Medium (M), and High $(\mathrm{H})$. The semantic variable related to the info variable 'Number of Nodes' is Low (L), Medium (M), and High (H).

The semantic up-and-down related to the output variable ART is Low (L), Medium (M) and High (H). The member functions for the input variables HopCount, SentCntrlPkt and number of nodes are appeared into fig 1 \& 2, and 3 correspondingly. The part work for the input variable dynamic routes TimedOut has appeared in fig 4. The exterior perspective observation on the representation has appeared in fig 5. Table.1 presents the standard support utilized in the model [8].

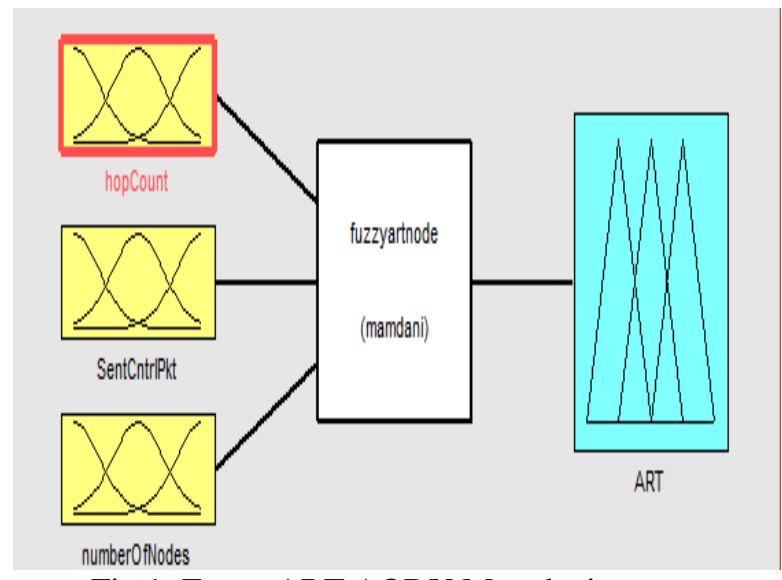

Fig.1: Fuzzy ART AODV Mamdani sugeno

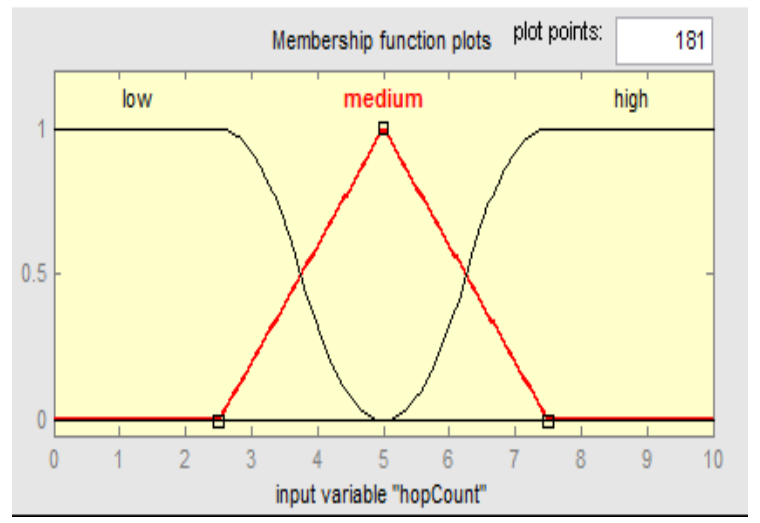

Fig.2: Element Node occupation for the Input Variable 'Hop Count'

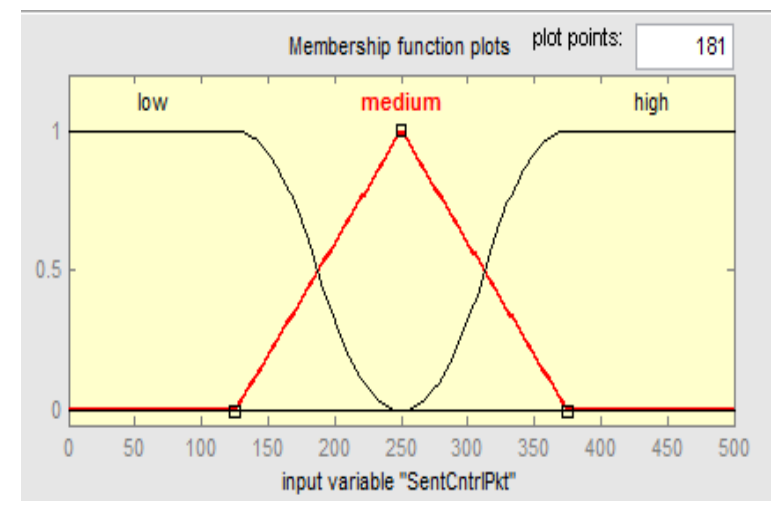

Fig.3: Member purpose for the Nnput changeable 'SentCntrlPkt' 


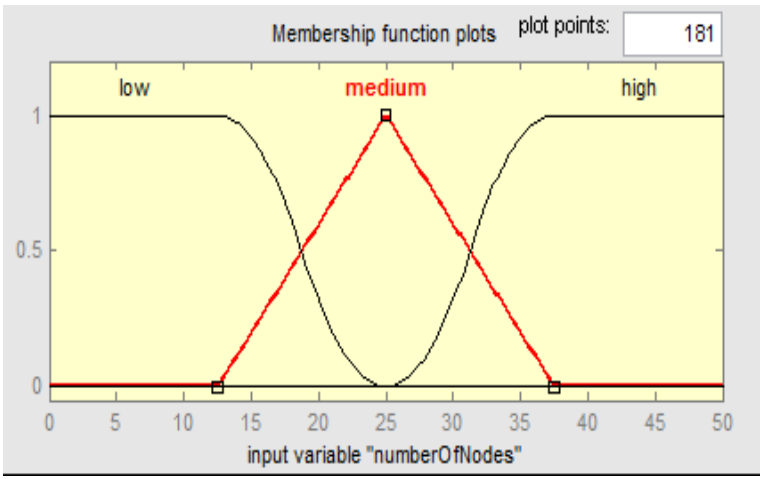

Fig.4: Node / Member functional operation for the input up-and-down Number of Nodes'

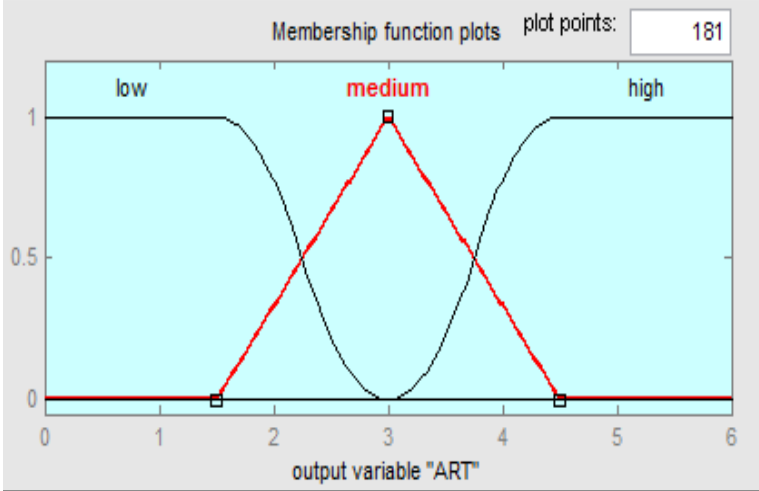

Fig.5: Member occupation for the output variable 'ART'

\begin{tabular}{|c|c|c|c|}
\hline $\begin{array}{c}\text { Hop } \\
\text { Count }\end{array}$ & $\begin{array}{c}\text { Sent } \\
\text { CntrlPkt }\end{array}$ & $\begin{array}{l}\text { Number } \\
\text { OfNodes }\end{array}$ & ART \\
\hline 1 & 1 & 1 & 3 \\
\hline 1 & 1 & 2 & 3 \\
\hline 1 & 1 & 3 & 2 \\
\hline 1 & 2 & 1 & 3 \\
\hline 1 & 2 & 2 & 2 \\
\hline 1 & 2 & 3 & 2 \\
\hline 1 & 3 & 1 & 2 \\
\hline 1 & 3 & 2 & 2 \\
\hline 1 & 3 & 3 & 1 \\
\hline 2 & 1 & 1 & 3 \\
\hline 2 & 1 & 2 & 2 \\
\hline 2 & 1 & 3 & 2 \\
\hline 2 & 2 & 1 & 2 \\
\hline 2 & 2 & 2 & 2 \\
\hline 2 & 2 & 3 & 1 \\
\hline 2 & 3 & 1 & 2 \\
\hline 2 & 3 & 2 & 1 \\
\hline 2 & 3 & 3 & 1 \\
\hline 3 & 1 & 1 & 2 \\
\hline 3 & 1 & 2 & 2 \\
\hline 3 & 1 & 3 & 1 \\
\hline 3 & 2 & 1 & 2 \\
\hline 3 & 2 & 2 & 1 \\
\hline 3 & 2 & 3 & 1 \\
\hline 3 & 3 & 1 & 1 \\
\hline 3 & 3 & 2 & 1 \\
\hline 3 & 3 & 3 & 1 \\
\hline
\end{tabular}

*1-Low, 2-Medium, 3-high

Table.2: Fuzzy rule base 


\section{SIMULATION ENVIRONMENT}

Network Simulation software specifically called as OPNET, NS2, GloMoSim, and Qualnet, etc., act as a crucial tasks toward estimation the network performance. OPNET is utilized during this simulation process [9] [14].

On the way to calculate the performance of FBARTAODV, different Simulations are conduct in network Size (10 Nodes, and 25 Nodes), and the execution of experiment output using Simulation parameters finally comes results shown in Table 2.

\begin{tabular}{|c|c|}
\hline Routing Protocols & AODV, FBARTAODV \\
\hline Simulation Time & $600 \mathrm{~s}$ \\
\hline Area (sq. m) & $1500 \times 1500$ \\
\hline Nodes & 10,25 \\
\hline Transmission Power & $0.005 \mathrm{~W}$ \\
\hline Data Rate & $1 \mathrm{Mbps}$ \\
\hline WLAN protocol & $802.11 \mathrm{~g}$ \\
\hline Maximum Queue Size & 4 \\
\hline Active Route Timeout & $3 \mathrm{~s}, 4.87 \mathrm{~s}$ \\
\hline
\end{tabular}

Table.2: Simulation Environment parameter

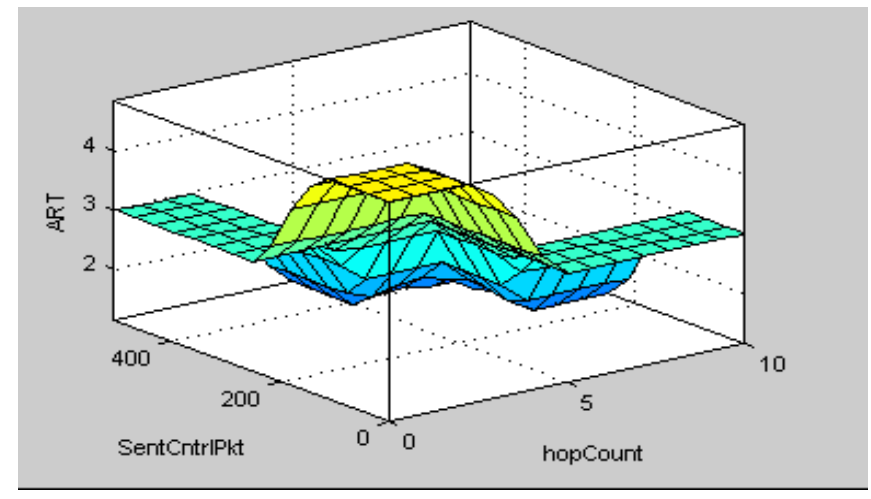

Figure 6: Surface viewer of the FBARTAODV

The performance of AODV and FBARTAODV be analyze in the metrics to be exact average end-end delay and standard Throughput.

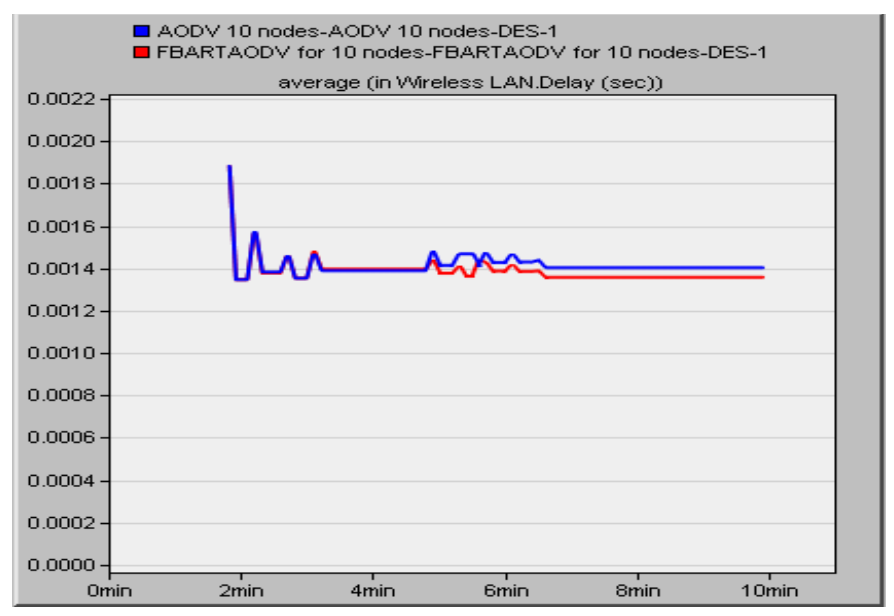

Fig.7: difference of average End-to-End Delay (Seconds in time) by 10 Nodes 




Fig.8: difference of average End-to-End Delay (Seconds in Time) among 25 Nodes

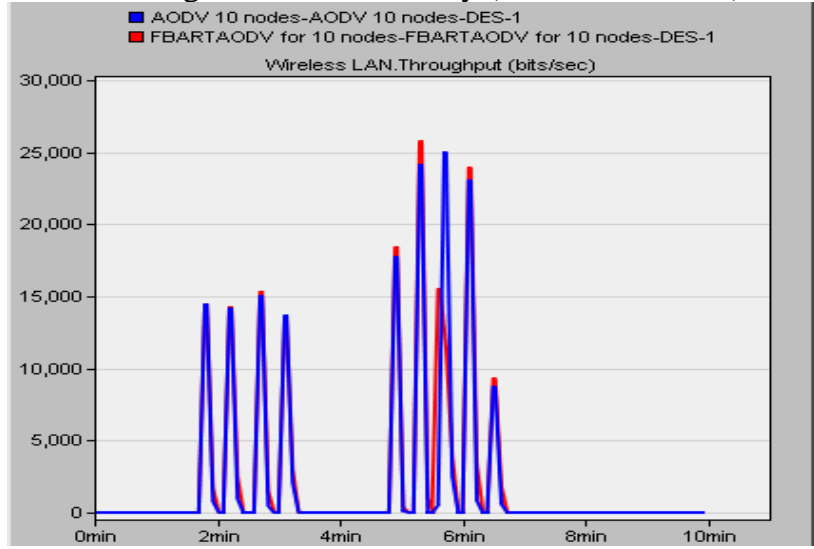

Fig.9: Deviation of Throughput (BPS) through 10 Nodes



Fig.10: Deviation of Throughput (BPS) by 25 Nodes

\section{Results}

The performance of AODV and FBARTAODV is evaluated among the evaluating throughput. Throughputs elaborate the whole quantity of information acknowledged by the fastidious recipient in the simulation time, the performance is analyze via altering nodes of simulation, and the outcome is depicting in Tables. $3 \& 4$. In Table-3, for 10 Nodes of simulation, it's be exhibit to FBARTAODV through superior series, such as 25,866.666 than ARTAODV. For ART output parameter FBARTAODV protocol gives better result than the ARTAODV protocol [12].

The Outcome of the evidence is clearly on fig.11. Even if ART changes in both ARTAODV and FBARTAODV the delay remains constant. Fuzzy based ARTAODV and ARTAODV the delay remains same. For the 10 nodes simulation, even if Fuzzy based ARTAODV and ARTAODV, the ART value changes it does not effect on the delay [11]. The Fuzzy based ARTAODV is showing better throughput, when compare to the ARTAODV. The Throughput values are co-related to the ART values. If the values of ART change 
correspondingly the Throughput values also changes. Fuzzy based ARTAODV gives better quality of service when compare to the ARTAODV.

In table 4, If Fuzzy based approach is applied on aodv the result is better than AODV for 25 nodes of simulation. It is exhibited that ARTAODV is increased the throughput value. When FBARTAODV ROUTING PROTOCOL gives the throughput values is 39499, where as ARTAODV routing protocols throughput value is 35520.The throughput value is increased, i.e. 3979.There is a relation between the output parameters ART and throughput in increasing the result. It is also evident clearly from figure 12. The delay is same for both ARTAODV and FBARTAODV routing protocols even though throughput value changes [10].

The output values of ART and throughput impact on ARTAODV AND FBARTAODV. Even if ART changes in both ARTAODV and FBARTAODV the delay remains constant. For the 25 nodes simulation even if Fuzzy based ARTAODV and ARTAODV the ART value changes it does not effect on the delay. Fuzzy based ARTAODV is showing better throughput when compare to the ARTAODV. The Throughput values are corelated to the ART values. There is no relation in differences of the values between ART, THROUGHPUT AND DELAY.If the values of ART changes correspondingly the Throughput values also changes. Fuzzy based ARTAODV gives better quality of service when compare to the ARTAODV [14].

The Increased trougput percentage after incorporating fuzzy based ART on AODV routing protocol is caliculated from the below calculation for 10 nodes

Simulation Pecentage of Increment $=$

((Throuput of FBARTAODV)-(throughput of ARTAODV)/FBARTAODV)*100

$=((25,866.66-25,018.66) / 25,8666.666) * 100$

$=3.28 \%$

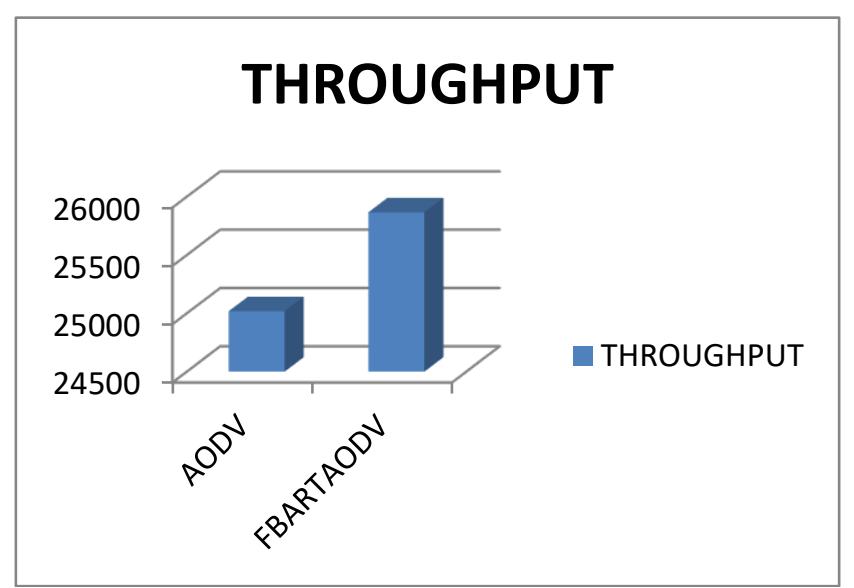

Fig.11: Evaluation throughput values between AODV and FBARTAODV for 10 nodes

Table 3: OPNET QOS Metrics for 10 nodes simulation

\begin{tabular}{|c|c|c|c|}
\hline $\begin{array}{c}\text { Parameter } \\
\text { S }\end{array}$ & ART & Delay & $\begin{array}{c}\text { Through } \\
\text { put }\end{array}$ \\
\hline ARTAOD & 3 & 0.00188 & $25,018.6$ \\
V & & 9 & 66 \\
\hline FBARTAO & 4.87 & 0.00188 & $25,866.6$ \\
DV & & 9 & 66 \\
\hline
\end{tabular}

The Increased trougput percentage after incorporating fuzzy based ART on AODV routing protocol is caliculated from the below calculation for 25 nodes simulation [13].

Pecentage of Increment $=$

((Throuput of FBARTAODV)-(throughput of ARTAODV)/FBARTAODV)*100

$=10.07 \%$

$$
=((39,498.666-35,520) / 39,498.666) * 100
$$

Table-4: OPNET QOS Metrics for 25 nodes simulation

\begin{tabular}{|c|c|c|c|}
\hline Parameters & ART & Delay & $\begin{array}{c}\text { Through } \\
\text { put }\end{array}$ \\
\hline
\end{tabular}




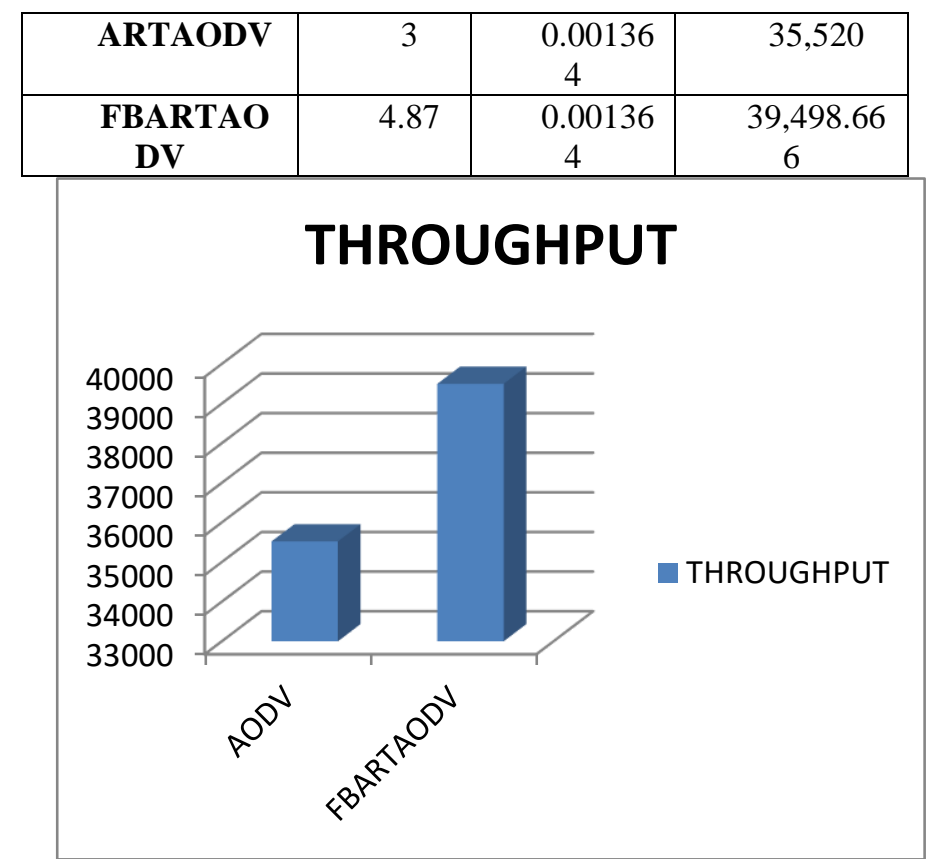

Fig.12: Comparison Throughput values between AODV and FBARTAODV for 25 nodes

\section{Conclusion and Future Scope}

The FBARTAODV planned have been contrast by the innovative AODV in performance. It is healthy notice to the projected FBARTAODV approach.

In this experimental research paper gives better way to understand and enhance the end-to - end connectivity with delay identification and construction based on the innovative method. AODV's fuzzy logic have seeing as exposed improvement contrast along with that of the earliest AODV and performs better in MANETs. Fuzzy based ARTAODV is showing better throughput when compare to the ARTAODV.

The Throughput values are co-related to the ART values. There is no relation in differences of the values between ART, THROUGHPUT AND DELAY. If the values of ART changes correspondingly the Throughput values also changes. Fuzzy based ARTAODV gives better quality of service when compare to the ARTAODV.

\section{References}

1. C. Perkins, “Ad Hoc Networking”, Addison-Wesley, 2001.

2. C. Perkins and E. M. Royer, "Ad-hoc On-Demand Distance Vector Routing," Proc. of the 2nd IEEE workshop on Mobile Computing Systems and Applications, New Orleans, LA, pp.

3. 90-100, February 1999.

4. C. Perkins, "Ad Hoc On Demand Distance Vector (AODV) routing”, Internet-Draft, draft-ietf-manetaodv-00.txt, Nov. 1997, Work in progress.

5. C-K. Toh, Wireless ATM and Ad Hoc Networks: Protocols and Architectures, Kluwer Academic Press, 1997

6. D. B. Johnson and D. A. Maltz, "Dynamic Source Routing in Ad Hoc Wireless Networks," in Fig. 7. Fuzzy ART values used by a node. Mobile Computing, edited by T.Imielinski and H. Korth, Ch. 5, pp. 153-181, Kluwer Academic Publishers, 1996.

7. V. Park and M. S. Corson, MANET Internet Draft “draft-ietf-manet-tora-spec-03.txt,"November 2000.

8. K. Paul, S. Bandyopadhyay, A. Mukherjee, and D. Saha, "Communication-Aware Mobile

9. Hosts in Ad-Hoc Wireless Network," Proc. Int'l Conf. Personal Wireless Comm., pp. 83-87, 1999.

10. B. Liang and Z. J. Haas, "Optimizing Route-Cache Lifetime in Ad Hoc Networks," Proc. of the 22th IEEE INFOCOM, San Francisco, CA, April 1-3, 2003.

11. S. Agarwal, A. Ahuja, J. Singh, and R. Shorey, "Route-Lifetime Assessment Based Routing (RABR) Protocol for Mobile Ad-Hoc Networks,” IEEE Int'l Conf. Comm., pp. 1697-1701, 2000. 
12. Y. Tseng, Y. Li and Y. Chang, "On Route Lifetime in Multihop Mobile Ad Hoc Networks", IEEE Trans. on Mobile Computing,, Vol. 2, No. 4, pp.366-376, Oct. 2003

13. Uppe Nanaji, Prof. S.Pallam Setty, "Investigation Misbehavior Configuration Nodes with Secure Neighborhood on Energy Consumption for DYMO Routing Protocol in MANETS", International Journal of Innovative Technology and Exploring

14. Uppe Nanaji, Prof. S.Pallam Setty, "Investigate the Impact of Buffer to Provide Security for DYMO in MANETS", Journal of Science, Technology and Development, Volume 9, Issue 12 December 2020.

15. Uppe Nanaji, Prof. S.Pallam Setty, "Investigating the Impact of Network Parameters on Wormhole Attack with ANODR Routing Protocol in MANET", Journal on Wireless Communication Networks, Volume 8, Issue 4, January-June 2020.

16. Dr.A.Senthil Kumar, Dr.G.Suresh, Dr.S.Lekashri, Mr.L.Ganesh Babu, Dr. R.Manikandan. (2021). Smart Agriculture System With E - Carbage Using Iot. International Journal of Modern Agriculture, 10(01), 928 - 931. Retrieved from http://www.modern-journals.com/index.php/ijma/article/view/690

17. Dr.G.Suresh, Dr.A.Senthil Kumar, Dr.S.Lekashri, Dr.R.Manikandan. (2021). Efficient Crop Yield Recommendation System Using Machine Learning For Digital Farming. International Journal of Modern Agriculture, 10(01), 906 - 914. Retrieved from http://www.modernjournals.com/index.php/ijma/article/view/688

18. Dr. R. Manikandan, Dr Senthilkumar A. Dr Lekashri S. Abhay Chaturvedi. "Data Traffic Trust Model for Clustered Wireless Sensor Network." INFORMATION TECHNOLOGY IN INDUSTRY 9.1 (2021): 1225-1229. Print. 